\title{
Protecting role of cosolvents in protein denaturation by SDS: a structural study
} Catherine Michaux*1, Jenny Pouyez ${ }^{1}$, Johan Wouters ${ }^{1}$ and Gilbert G Privé 2 Address: ${ }^{1}$ Chemistry department, CBS lab, CPTS group, 61 rue de Bruxelles, B-5000 Namur, Belgium and ${ }^{2}$ Division of Cancer Genomics and
Proteomics, Ontario Cancer Institute 101 College Street, Toronto, Ontario, M5G 1L7, Canada

Email: Catherine Michaux* - catherine.michaux@fundp.ac.be; Jenny Pouyez - jenny.pouyez@fundp.ac.be; Johan Wouters - johan.wouters@fundp.ac.be; Gilbert G Privé - prive@uhnres.utoronto.ca

* Corresponding author

Published: 3 June 2008

BMC Structural Biology 2008, 8:29 doi:10.1 186/1472-6807-8-29
Received: 17 March 2008

Accepted: 3 June 2008

This article is available from: http://www.biomedcentral.com/l472-6807/8/29

(c) 2008 Michaux et al; licensee BioMed Central Ltd.

This is an Open Access article distributed under the terms of the Creative Commons Attribution License (http://creativecommons.org/licenses/by/2.0), which permits unrestricted use, distribution, and reproduction in any medium, provided the original work is properly cited.

\begin{abstract}
Background: Recently, we reported a unique approach to preserve the activity of some proteins in the presence of the denaturing agent, Sodium Dodecyl Sulfate (SDS). This was made possible by addition of the amphipathic solvent 2,4-Methyl-2-PentaneDiol (MPD), used as protecting but also as refolding agent for these proteins. Although the persistence of the protein activity in the SDS/ MPD mixture was clearly established, preservation of their structure was only speculative until now.

Results: In this paper, a detailed X-ray study addresses the pending question. Crystals of hen eggwhite lysozyme were grown for the first time in the presence of MPD and denaturing concentrations of SDS. Depending on crystallization conditions, tetragonal crystals in complex with either SDS or MPD were collected. The conformation of both structures was very similar to the native lysozyme and the obtained complexes of SDS-lysozyme and MPD-lysozyme give some insights in the interplay of protein-SDS and protein-MPD interactions.

Conclusion: This study clearly established the preservation of the enzyme structure in a SDS/MPD mixture. It is hypothesized that high concentrations of MPD would change the properties of SDS and lower or avoid interactions between the denaturant and the protein. These structural data therefore support the hypothesis that MPD avoids disruption of the enzyme structure by SDS and can protect proteins from SDS denaturation.
\end{abstract}

\section{Background}

Sodium dodecyl sulfate (SDS) is a highly effective and widely used protein denaturant $[1,2]$. Our previous work has shown that amphipathic solvents, like 2-methyl-2,4pentanediol (MPD), a commonly used precipitant for crystallization studies [3], can protect proteins from SDS denaturation, and in several cases can drive the transition from the SDS-denatured state to a functional folded state [4]. This protecting effect of MPD is observed with a wide range of proteins including membrane proteins and soluble enzymes, and is not applicable if proteins are denatured in guanidine or urea, two other denaturant agents. In the case of hen egg-white lysozyme, SDS concentrations above $1.0 \mathrm{mM}$ abolished the activity of the enzyme in the absence of MPD. However, in $2 \mathrm{MMPD}$, the activity was preserved in the presence of SDS. In addition, when the enzyme was first denatured with SDS for 24 hours prior to adding MPD, full enzymatic activity was recov- 
ered in $2 \mathrm{M}$ MPD following a further 24 hour incubation period. Although the persistence of the enzyme activity in the SDS/MPD mixture was clearly established, preservation of its structure was only speculative until now.

In the present contribution, a detailed X-ray study addresses the pending question. Crystals of hen egg-white lysozyme could be grown for the first time in a SDS/MPD medium, providing support that adding MPD to proteins can avoid SDS denaturation. The obtained complexes of SDS-lysozyme and MPD-lysozyme give some insights in the interplay of protein-SDS and protein-MPD interactions. A previous report described the structure of crosslinked lysozyme crystals soaked in SDS solutions [5]. In the latter, unlike both structures described in this paper, SDS was found at three different locations inside the protein inducing a major structural deformation in the interior of lysozyme.

\section{Results and discussion \\ Crystallization}

Crystals of hen egg-white lysozyme solubilized in $4 \mathrm{mM}$ SDS, a usually denaturing condition, and 2 M MPD were obtained, without any cross-linking, contrary to the study of Yonath et al. [5], in two different conditions (see Materials and Methods). Tetragonal crystals, called "form I" crystals, were obtained from a classical sodium acetate solution at $\mathrm{pH}$ 4.6. In this condition, few MPD, slightly volatile, is expected to remain in the drop after equilibration of the protein droplet with the MPD-free reservoir solution (Table 1). To enhance the concentration of SDS and MPD into the drop, and taking into account results from the literature [6], crystals were also obtained by equilibrating protein solutions with reservoir solutions of $50 \mathrm{mM}$ Tris $\mathrm{pH} 8,70 \% \mathrm{MPD}$ and $6 \mathrm{mM}$ SDS resulting in "form II" crystals. Both crystals belong to the same tetragonal space group, $\mathrm{P}_{3} 2{ }_{1} 2$. Form I crystals diffracted X-rays to 2.3 and form II diffracted to $1.75 \AA$.

Table I: Statistics of data collection and structure refinement

\begin{tabular}{|c|c|c|}
\hline & Form I & Form II \\
\hline Expected MPD concentration in the drop after equilibration & close to $0 \mathrm{M}$ & $>4 M$ \\
\hline Expected SDS concentration in the protein droplet & $\sim 2 \mathrm{mM}$ & $\sim 5 \mathrm{mM}$ \\
\hline \multicolumn{3}{|c|}{ Data collection } \\
\hline Space group & $\mathrm{P}_{3} \mathrm{2}_{1} \mathrm{2}$ & $\mathrm{P}_{3} \mathrm{2}_{1} \mathrm{2}$ \\
\hline Unit-cell parameters () & $\mathrm{a}=\mathrm{b}=77.59, \mathrm{c}=37.57$ & $a=b=77.90, c=37.53$ \\
\hline Maximum resolution () & 2.3 & 1.75 \\
\hline Unique reflections & 5468 & 12247 \\
\hline Redundancy & 8.1 & 10.1 \\
\hline Completeness (\%) & $99.7(100)$ & $99.7(99.9)$ \\
\hline Avg. $I / \sigma$ & $21.9(8.5)$ & $18.7(3.2)$ \\
\hline $\mathbf{R}_{\text {merge }}(\%)$ & $8.22(22.72)$ & $4.5(20.2)$ \\
\hline \multicolumn{3}{|c|}{ Refinement statistics } \\
\hline $\mathbf{R}(\%)^{\mathbf{a}}$ & 20.18 & 17.03 \\
\hline $\mathbf{R}_{\text {free }}(\%)^{\mathrm{a}}$ & 21.40 & 20.84 \\
\hline RMSD bond lengths () & 0.021 & 0.066 \\
\hline $\begin{array}{c}\text { RMSD angle distances () RMSD bond angles }\left({ }^{\circ}\right) \\
\left.\text { Average B value ( }{ }^{2}\right)\end{array}$ & 1.92 & 0.061 \\
\hline Protein atoms & $14.9 \mid$ & 14.63 \\
\hline MPD molecules & l & 53.47 \\
\hline SDS molecule & 45.94 & l \\
\hline Water molecules & 20.66 & 26.64 \\
\hline $\begin{array}{l}\text { Ramachandran plot } \\
\text { Most favored, additional, generously allowed (\%) }\end{array}$ & $85.0 / 13.3 / 1.8$ & $89.4 / 10.6 / 0.0$ \\
\hline No. of MPD molecules & 0 & 2 \\
\hline No. of SDS molecules & 1 & 0 \\
\hline No. of $\mathrm{Na}$ ion & 0 & I \\
\hline No. of $\mathrm{Cl}$ ion & 0 & 2 \\
\hline No. of water molecules & 69 & 118 \\
\hline
\end{tabular}

Values listed in parentheses are for the highest resolution.

${ }^{a} R_{\text {factor }}=\sum|| F_{o}|-| F_{c}|| \sum\left|F_{o}\right| \cdot R_{\text {free }}$ was calculated with $5 \%$ of the reflections set aside randomly throughout the refinement. 


\section{Structure overview}

Unlike the one obtained by Yonath et al [5], the overall conformation of both structures is very similar to native lysozyme (PDB code 1Z55). The RMSD values calculated using the $\mathrm{C}_{\alpha}$ atoms, after superimposition with the native structure, are 0.27 and $0.20 \AA$ for form I and form II crystals, respectively (Fig. 1). No large structural changes are observed and the interior of the enzyme is intact. The most significant variations are observed at the surface of the proteins in loops where electron densities are less well-defined (for flexible residues like arginine and lysine). These differences are probably due to uncertainties from the model or intrinsic thermal behavior.

The presence of high concentration of MPD can therefore avoid disruption of the structure of the enzyme by SDS. Indeed, as shown by Yonath [5], SDS, by binding deeply into the hydrophobic core of the protein, induces separation of the two wings of lysozyme. In addition, the form I crystal, where few MPD is expected to remain in the drop, shows that MPD was able to induce irreversibly the correct folding of lysozyme in the presence of a denaturing concentration of SDS (2 mM).

\section{Interaction of SDS or MPD with lysozyme}

Depending on the used reservoir solution, different small molecules were found co-crystallized with lysozyme (Table 1). SDS and MPD molecules could be identified unambiguously in the density maps due to their characteristic shape. With condition II buffer, a first MPD molecule, in the S configuration, occupies the C-subsite in the sugar-binding cleft of the protein formed by residues Asn59, Trp63, Ile58, Ala107 and Trp108 (Fig. 2). This was also found to be the binding site of alcohol molecules like ethanol, propanol, butanol and pentanol [7] and of denaturants, used at non-denaturing concentrations, like DMSO, guanidinium hydrochloride [8] and urea $[9,10]$. This is in agreement with the assumption that generally MPD molecules prefer to bind to hydrophobic site and MPD binding is penetrative, leading to displacement of water molecules in grooves and cavities [3]. The hydrophobic part of the molecule interacts with Trp108 (contact $\leq 3.5$ ) and both alcohol groups are $\mathrm{H}$ bonded to the backbone of Asn59 and to Trp63, respectively. A second MPD molecule, in the S configuration, is bound on the surface between two lysozyme molecules, close to Arg114 (Fig. 3). No molecules of SDS were observed in the electronic density map.

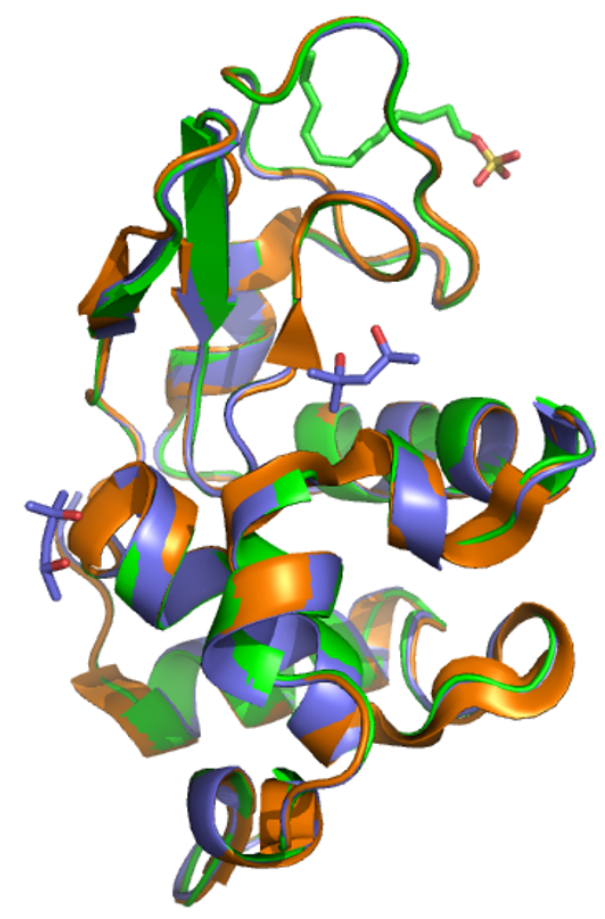

Figure I

Superimposition of crystal structure of lyzozyme in the native state (IZ55; orange), co-crystallized with SDS (form I; green) and with SDS/MPD (form II; blue). 

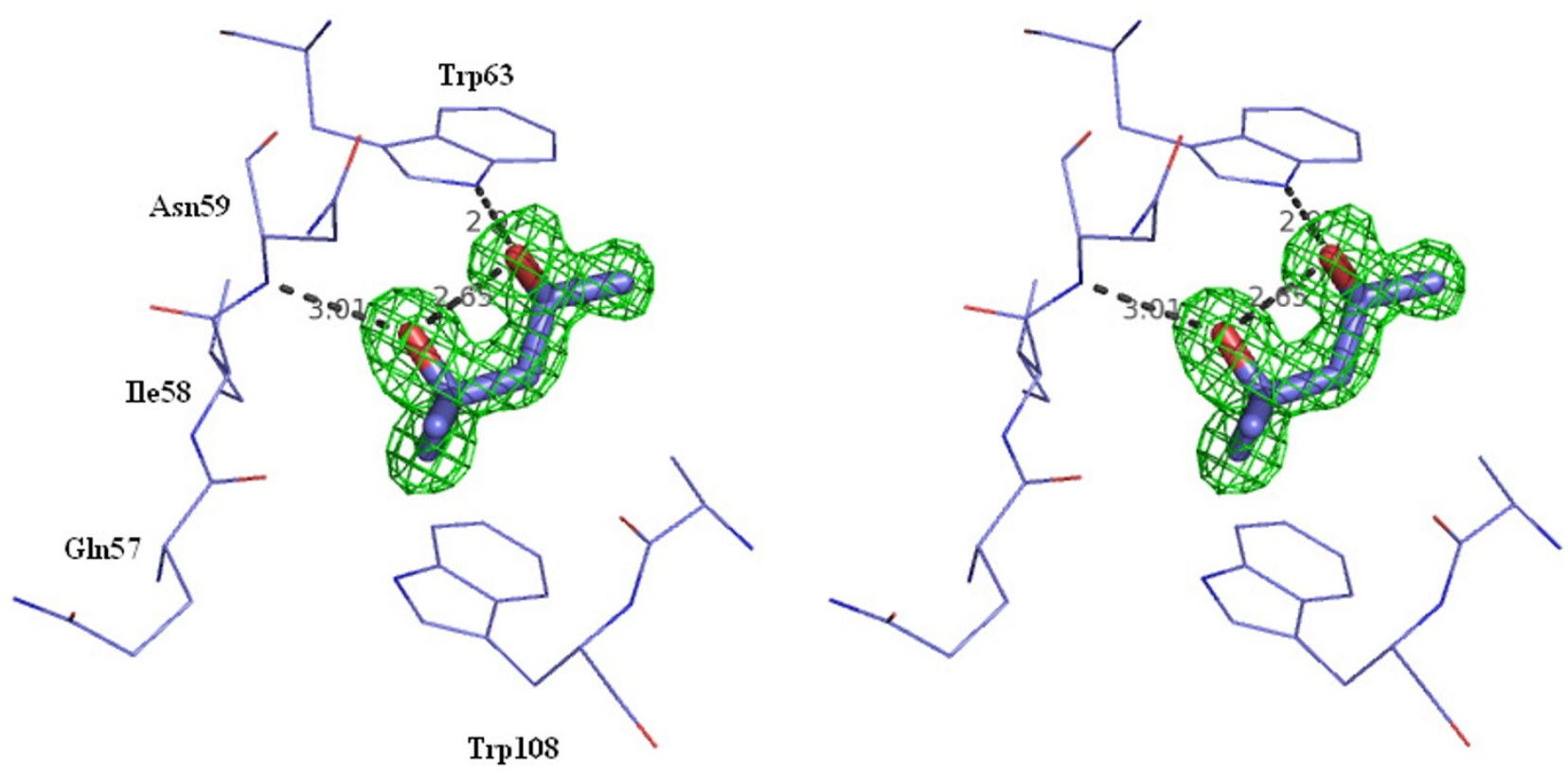

\section{Figure 2}

Stereoview of the complex between lysozyme and MPD in the C-subsite. Electron density of the $2 F_{O}-F_{C}$ map is contoured at I $\sigma$ level for MPD.

The S configuration of both MPD molecules is quite clear by lowering the contour level to around 0.6 but at this stage, it is impossible to deduce that S-MPD is more stabilizing than the $\mathrm{R}$ one.

A comparison of the above structure with the one of lysozyme crystallized in the presence of MPD, without SDS, (PDB code 1DPW, 1.64 ) [6] yields RMSD of 0.14 for the superposition of $\mathrm{C}_{\alpha}$ atoms. The location of the second MPD molecule in the present study matches the one previously described, except the configuration which is switched. The water molecule between MPD and Arg114 is also conserved. Moreover, two chloride ions were identified in the same binding site as in the 1DPW structure. Additionally, a sodium ion was observed ligated to the main chain carbonyl oxygen's of residues Ser60, Cys64, Arg73, O $\gamma$ of Ser72 side chain, and two water molecules. This sodium ion binding site was present in the enzyme in the presence of low concentration of DMSO and guanidinium chloride [8].

With the condition I buffer, as expected, no electron density was observed for MPD whereas a SDS molecule was found on the surface of lysozyme, exposed to the solvent. As suggested by Weiss et al, MPD may only be able to bind lysozyme at high $\mathrm{pH}$ values and/or at high concentration. SDS is loosely bound, as indicated by its temperature factors (70-80 $\AA$ for the sulphate tail). The SDS sulphate is salt bridged to Arg73 (Fig. 4) and the hydrocarbon tail makes contacts with Ser60, Cys64-Pro70, Ser72-Asn74. The binding position is different from those described in the SDS-lysozyme complex described earlier where the SDS molecules bind deeply into the protein [5]. Indeed, the hydrophobic interactions of SDS with the core of the protein are assumed to be lowered in the presence of MPD. In addition, the binding of SDS does not alter the 

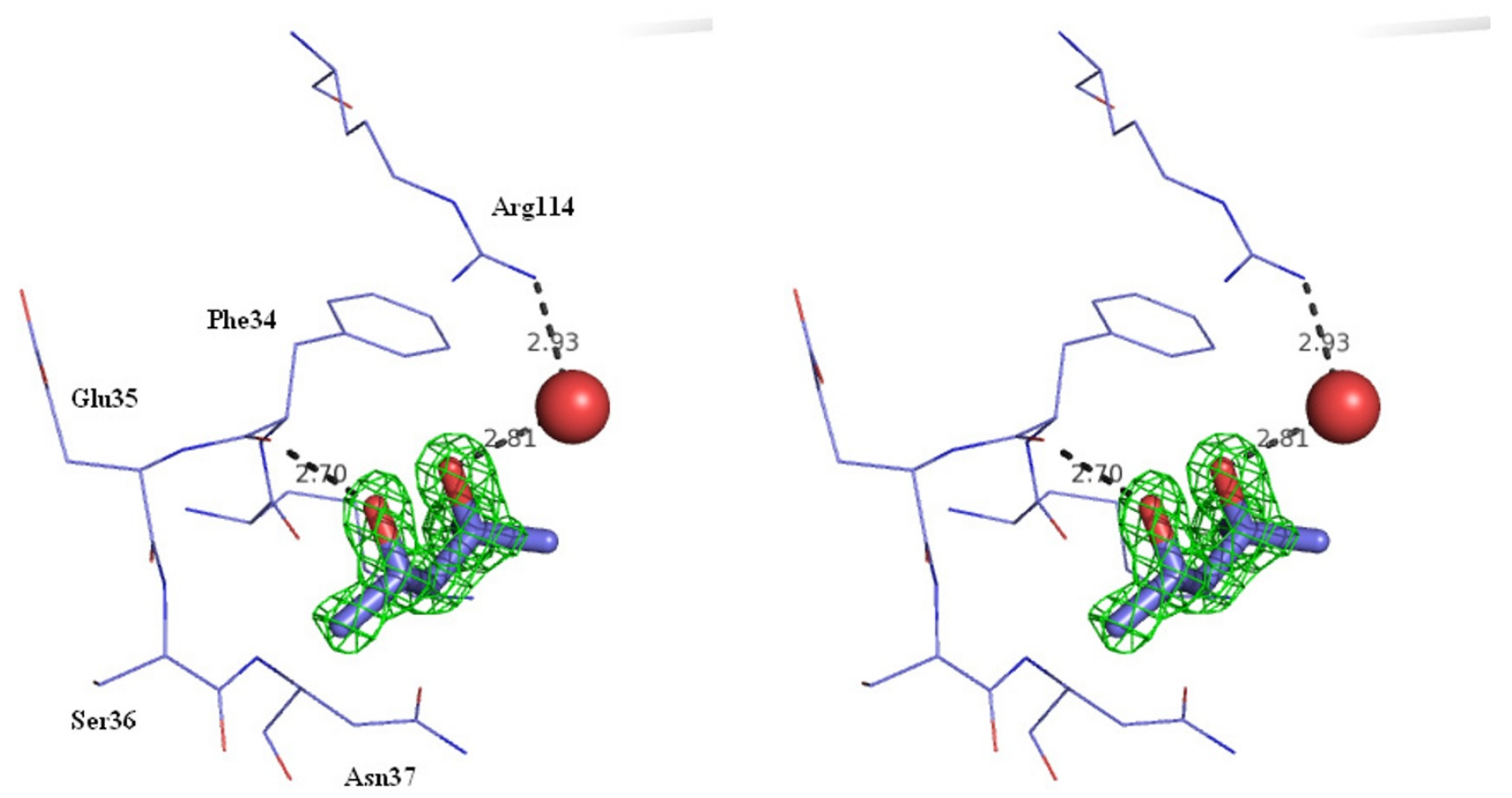

Figure 3

Stereoview of the complex between lysozyme and MPD on the surface of the protein. Electron density of the $2 F_{O^{-}}$ $F_{C}$ map is contoured at I $\sigma$ level for MPD.

structure of lysozyme. In this structure, no sodium or chloride ions were observed. It is worth noting that this study presents one of the very few structures of proteins co-crystallized with a denaturing concentration of SDS in its native form.

\section{Conclusion}

This study, where crystals of lysozyme were grown for the first time in the presence of the amphipathic solvent MPD and denaturing concentrations of SDS, clearly established the preservation of the enzyme structure in a SDS/MPD mixture. It is hypothesized that high concentrations of MPD, changing the properties of SDS, would lower (condition I) or avoid (condition II) interactions between SDS and the protein. Indeed, in the form II crystal, even though it contains higher SDS concentration, but also higher MPD concentration, than in the form I, no SDS molecule was observed. This assumption is in agreement with the size-exclusion chromatography study described earlier [4], demonstrating that the protein no longer interacts strongly with SDS in a MPD buffer system. These structural data therefore support the hypothesis that MPD can protect proteins from SDS denaturation.

In addition, it is worth noting that this contribution shows one of the very few structures of proteins, in its native form, co-crystallized with SDS.

\section{Methods}

\section{Crystallization}

Lyophilized hen egg-white lysozyme, obtained from Sigma, was solubilized in $4 \mathrm{mM}$ SDS, $50 \mathrm{mM}$ Tris pH8, $150 \mathrm{mM} \mathrm{NaCl}$ and $2 \mathrm{M} \mathrm{MPD} \mathrm{(racemic} \mathrm{form)} \mathrm{(around} 10$ $\mathrm{mg} / \mathrm{ml}$ protein). Crystals were grown at room temperature by the hanging drop vapor diffusion method using two different conditions. First $4 \mu \mathrm{l}$ of the protein solution was mixed with $4 \mu \mathrm{l}$ of a MPD-free reservoir solution containing $100 \mathrm{mM}$ sodium acetate buffer $\mathrm{pH} 4.6$ and $2 \mathrm{M}$ sodium formate (condition I), and equilibrated with $1 \mathrm{~mL}$ of reservoir solution. In the second condition, the reservoir solution consists of $50 \mathrm{mM}$ Tris $\mathrm{pH} 8,70 \%(\sim 4.6 \mathrm{M})$ MPD (racemic form) and $6 \mathrm{mM}$ SDS (condition II). 


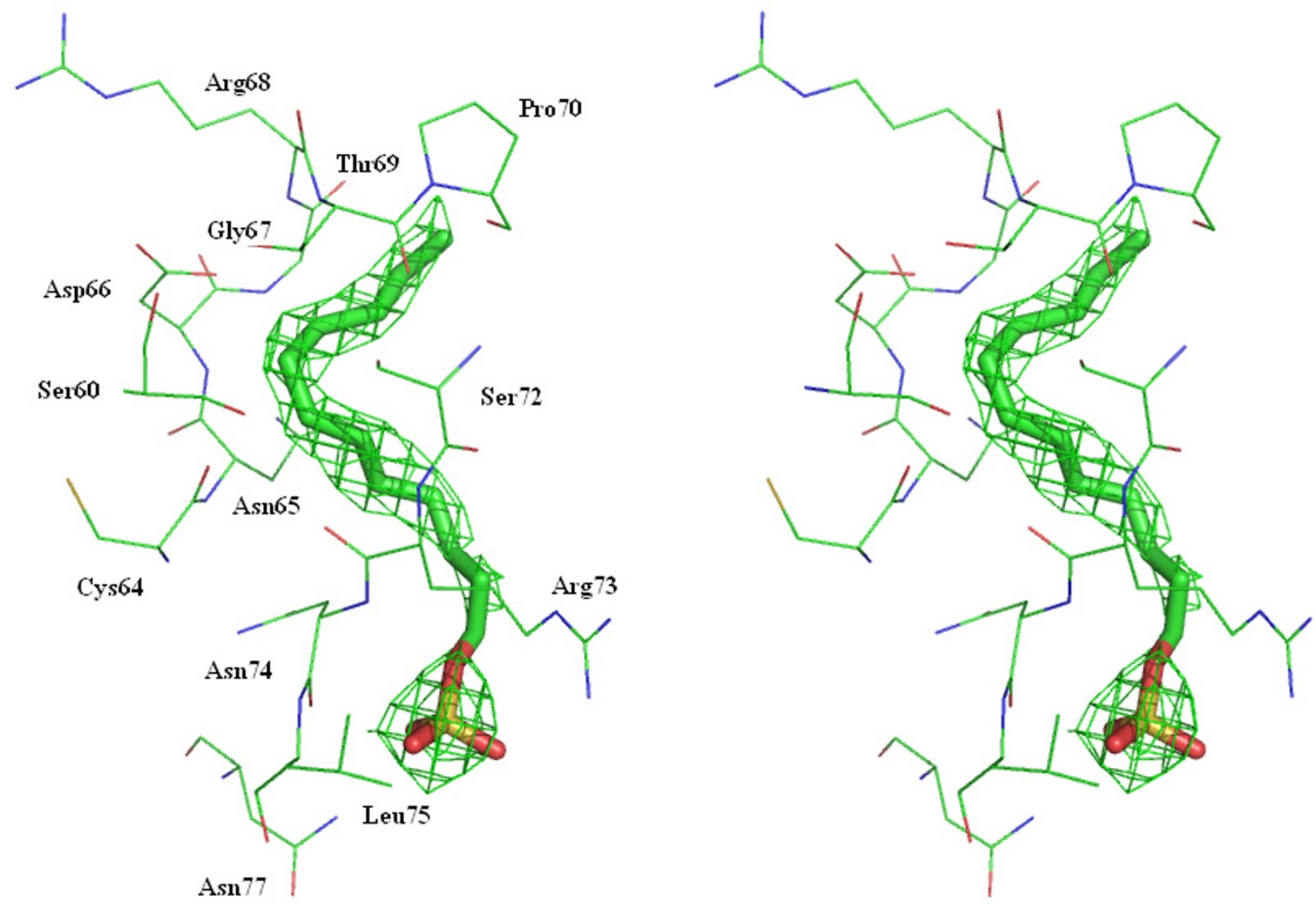

Figure 4

Stereoview of the complex between SDS and the enzyme. Electron density of the $2 F_{O^{-}} F_{C}$ map is contoured at $I \sigma$ level for SDS. Figures I to 4 were generated by using PyMOL [I7].

\section{Data collection, processing and refinement}

Crystals harvested directly from mother liquor were flashfrozen in a $100 \mathrm{~K}$ nitrogen stream with no added cryoprotectant. Diffraction data of the form I crystals were collected using a Bruker MICROSTAR generator with a Bruker Proteum X8 CCD X-ray detector. The crystal-to-detector distance was $60 \mathrm{~mm} ; 180$ images $\left(0.5^{\circ}\right.$ as oscillation range/image) with a 120 sec exposure time per image were collected; SAINT-Plus/Proteum was used to process the data.

For the form II crystals, a Gemini Ultra R system (4-circle kappa platform, Ultra Enhanced Cu Source, Ruby CCD detector) was used. The crystal-to-detector distance was 50 mm; 180 images with a $90 \mathrm{sec}$ exposure time per image were collected; CrysAlis CCD and CrysAlis RED were used to process the data.
A molecular replacement solution was found using Phaser [11] with the molecular model of the native lysozyme (PDB entry 1Z55). Refinement was performed either with the Shelxl97 (Form II) [12] or Refmac5 (Form I) program [13]. Electron density maps were inspected with the graphic program Xtalview (Form II) [14] or Coot (Form I) [15], and the quality of the model was analyzed with the program Procheck [16]. The atomic coordinates and structure factors have been deposited in the Protein Data Bank (3B6Land 3B72).

\section{Authors' contributions}

CM carried out the crystallographic studies and wrote the manuscript. JP participated in the crystallogenesis experiments. GGP conceived of the study, and participated in its design and coordination and helped to draft the manuscript. JW helped in the study coordination and in the corrections of the paper. All authors read and approved the final manuscript. 


\section{Acknowledgements}

CM is grateful to FNRS for financial support. This work was funded in part by a CIHR grand to GGP.

\section{References}

I. Gimel JC, Brown W: A light-scattering investigation of the sodium dodecyl sulfate-lysozyme system. J Chem Phys 1996, 104:8II2-8II7.

2. Otzen DE: Protein unfolding in detergents: effect of micelle structure, ionic strength, $\mathrm{pH}$, and temperature. Biophys J 2002, 83:2219-2230.

3. Anand K, Pal D, Hilgenfeld R: An overview on 2-methyl-2,4-pentanediol in crystallization and in crystals of biological macromolecules. Acta Cryst D 2002, 58: 1722-1728.

4. Michaux C, Pomroy N, Privé GG: Refolding SDS-denatured proteins by the addition of amphipathic cosolvents. J Mol Biol 2008, 375: $1477-1488$.

5. Yonath A, Podjarny A, Honig B, Sielecki A, Traub W: Crystallographic studies of protein denaturation and renaturation. 2. Sodium dodecyl sulfate induced structural changes in triclinic lysozyme. Biochemistry 1977, 16:|4|8-|424.

6. Weiss MS, Palm GJ, Hilgenfeld R: Crystallization, structure solution and refinement of hen egg-white lysozyme at $\mathrm{pH} 8.0$ in the presence of MPD. Acta Cryst D 2000, 56:952-958.

7. Deshpande A, Nimsadkar S, Mande SC: Effect of alcohols on protein hydration: crystallographic analysis of hen egg-white lysozyme in the presence of alcohols. Acta Cryst D 2005, 6I:1005-1008.

8. Mande SC, Sobhia ME: Structural characterization of proteindenaturant interactions: crystal structures of hen egg-white lysozyme in complex with DMSO and guanidinium chloride. Protein Eng 2000, I3:133-141.

9. Pike AC, Acharya KR: A structural basis for the interaction of urea with lysozyme. Protein Sci 1994, 3:706-7I0.

10. Salem M, Mauguen Y, Prangé T: On the edge of the denaturation process: application of $X$-ray diffraction to barnase and lysozyme cross-linked crystals with denaturants in molar concentrations. Biochim Biophys Acta 2006, 1764:903-912.

II. Storoni LC, McCoy AJ, Read RJ: Likelihood-enhanced fast rotation functions. Acta Cryst D 2004, 60:432-438.

12. Sheldrick GM, Schneider TR: SHELXL: High-resolution refinement. In Methods in Enzymol Volume 277. Elsevier, San Diego, CA, Etats-Unis; 1997:319-343. Sheldrick GM: SHELXS97 and SHELXL97. Université de Göttingen, Allemagne 1997

13. Murshudov GN, Vagin AA, Dodson E]: Refinement of Macromolecular Structures by the Maximum-Likelihood Method. Acta Cryst 1997, D53:240-255

14. McRee DE: XtalView/Xfit - A Versatile Program for Manipulating Atomic Coordinates and Electron Density. J Struct Biol 1999, I 25: 156-165.

15. Emsley P, Cowtan K: Coot: model-building tools for molecular graphics. Acta Cryst 2004, D60:2/26-2/32.

16. Laskowski RA, MacArthur MW, Moss DS, Thornton JM: PROCHECK: a program to check the stereochemical quality of protein structures. J App Cryst 1993, 26:283-291.

17. DeLano WL: The PyMOL Molecular Graphics System. 2002 [http://www.pymol.org]. DeLano Scientific, San Carlos, CA, USA

Publish with Biomed Central and every scientist can read your work free of charge

"BioMed Central will be the most significant development for disseminating the results of biomedical research in our lifetime. "

Sir Paul Nurse, Cancer Research UK

Your research papers will be:

- available free of charge to the entire biomedical community

- peer reviewed and published immediately upon acceptance

- cited in PubMed and archived on PubMed Central

- yours - you keep the copyright

Submit your manuscript here:

http://www.biomedcentral.com/info/publishing_adv.asp
BioMedcentral 